\title{
CONTROLE PATRIMONIAL DE BENS IMÓVEIS COM BASE NAS DIMENSÕES DE GOVERNANÇA PÚBLICA ESTABELECIDOS PELA ORGANIZAÇÃO INTERNATIONAL FEDERATION OF ACCOUNTANTS (IFAC): UM ESTUDO DE CASO NA UFSM
}

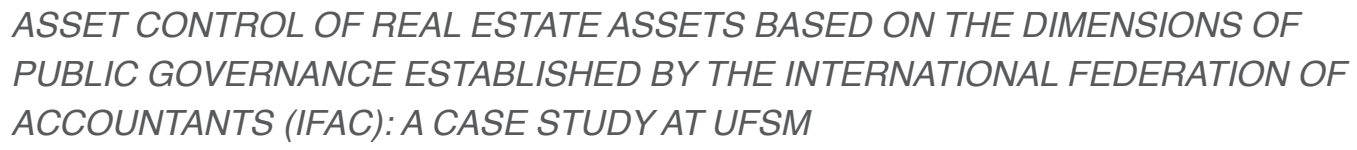

Ana Paula da Costa Mayer

Universidade Federal de Santa Maria, Santa Maria, RS, Brasil E-mail:paulamayer@ufsm.br

Cristiane de Paula Bachmann

Universidade Federal de Santa Maria, Santa Maria, RS, Brasil E-mail: chrys.bachmann@bol.com.br

Laura Beatriz Hartmann Universidade Federal de Santa Maria, Santa Maria, RS, Brasil E-mail: laura.rp.ufsm@gmail.com

Breno Augusto Diniz Pereira Universidade Federal de Santa Maria, Santa Maria, RS, Brasil E-mail: brenodpereira@gmail.com

Nelson Guilherme Machado Pinto Universidade Federal de Santa Maria, Santa Maria, RS, Brasil E-mail: nelguimachado@hotmail.com

Recebido em: 0103.2017 - Aceito em: 10.08.2017

\section{RESUMO}

A Governança Pública agregou importantes conceitos e, especialmente, instrumentos para a concretização de uma relação mais íntegra, transparente e responsável entre os gestores públicos e a sociedade em geral. Assim, o presente estudo tem como objetivo analisar o controle patrimonial dos bens imóveis da Universidade Federal de Santa Maria (UFSM) com base nas dimensões de governança pública estabelecidas pela organização International Federation of Accountants (IFAC), considerando a dimensão "controle". Para tanto, o levantamento de dados foi feito através de entrevista com o Pró-Reitor de Administração da instituição, com questões adaptadas a partir das práticas de governança pública recomendadas pela IFAC. A presente pesquisa pode ser definida, quanto aos seus objetivos, como descritiva e de abordagem qualitativa. Os resultados da pesquisa, de um modo geral, demonstram a absorção de valores e princípios mínimos de governança recomendados pela IFAC na UFSM, pois observa-se a adoção de boas práticas, o que implica transparência e promoção da accountability para a instituição. 
PALAVRAS-CHAVE: Governança pública; Controle; Patrimônio de Bens Imóveis.

\section{ABSTRACT}

Public Governance added important concepts and, especially, instruments to achieve a fuller relationship, transparency and accountability among public servants and society. Since public governance has assumed its principles as duties, balance control checking has been more prized. Thus, this study aims to analyze the balance control of immovable property of UFSM, based on public governance dimensions established by IFAC organization - The International Federation of Accountants especially focused on "Control" dimension. For this purpose, the data will be collected through interviews with managers from DEMAPA (Department of Materials and Property) with questions adapted from the public governance practices recommended by the IFAC. This research is defined as descriptive, with a qualitative approach. The results of the research, in general, demonstrate the absorption of values and minimum principles of governance recommended by IFAC in UFSM, since it is observed the adoption of good practices which implies transparency and promotion of accountability for the institution.

KEYWORDS: Public governance; Control; Immovable Property.

\section{INTRODUÇÃO}

O poder e o dever de agir são próprios dos gestores públicos, entretanto devem ser fundamentados nos princípios constitucionais aplicados à administração e à governança pública, o que, obviamente, necessita de avaliação para mensuração de sua efetividade. Os mecanismos de controle interno e externo foram instituídos para que a atuação estatal não se afastasse da legalidade; dessa forma, o controle patrimonial é realizado com o objetivo de garantir a existência de informações confiáveis sobre a localização física, movimentações e estado de conservação dos bens imóveis.

Nesse contexto, faz-se necessário referenciar os princípios gerais da Administração Pública, norteadores das ações: legalidade, moralidade, impessoalidade, eficiência e publicidade. Toda e qualquer ação de âmbito público exige o respeito às leis, normas, decretos e demais instrumentos legais estabelecidos; exige, ainda, respeito à moralidade (estabelecida socialmente). Além disso, toda ação deve ser planejada para o alcance de resultados com o menor custo e todas as ações devem se tornar públicas, de conhecimento geral da população, com o intuito de garantir controle e transparência. 
As informações contábeis sobre o patrimônio, registradas no Sistema Integrado de Administração Financeira (Siafi), seguramente não atenderão à realidade do patrimônio físico se não houver um controle patrimonial eficaz, colocando em dúvida, portanto, a confiabilidade dos balanços patrimoniais, bem como os procedimentos de prestação de contas. Também deve ser enfatizado, conforme Bernardes (2009), que os estudos que tratamdo controle patrimonial ainda são incipientes no Brasil, onde os setores de patrimônio das instituições públicas brasileiras, tanto federais quanto municipais e estaduais, necessitam de estudos que aprofundem e disseminem o domínio de conhecimentos existentes nas ilhas de experiência que os cercam, devido à falta de publicações versando sobre esse tema.

Assim, realizar uma análise do controle patrimonial de bens imóveis da UFSM com base nos princípios de governança pública possibilita a obtenção de conhecimento teórico sobre o tema e, consequentemente, o aperfeiçoamento dessa atividade na prática, o que justifica a importância desta pesquisa. O presente estudo leva em consideração o seguinte problema de pesquisa: de que modo o controle patrimonial de bens imóveis da UFSM atende às práticas de governança pública recomendadas pela organização International Federation ofAccountants (IFAC) na dimensão "controle"?

O objetivo geral é analisar o controle patrimonial dos bens imóveis da UFSM, com base nas dimensões de governança pública estabelecidas pela IFAC. Os objetivos específicos são verificar o controle patrimonial de bens imóveis da UFSM de acordo com as práticas de governança pública recomendadas pela IFAC, considerando a dimensão "controle", e descrever os procedimentos utilizados no controle patrimonial de bens imóveis da UFSM. A contribuição deste estudo está em demonstrar que o controle patrimonial da UFSM pode ser reestruturado, por meio do estabelecimento de normas e procedimentos padronizados que visem promover a observância dos princípios da Administração Pública.

O presente artigo está estruturado, além desta introdução, em quatro seções. $\mathrm{Na}$ segunda seção, é apresentado o referencial teórico. Na terceira, apresentam-se os procedimentos metodológicos aplicados e, na seção seguinte, a discussão e análise dos resultados. Por fim, são apresentadas as principais conclusões do trabalho.

\section{REFERENCIAL TEÓRICO}

\subsection{Governança pública}

A governança, enquanto conceito e prática, adquire destaque na passagem dos séculos $\mathrm{XX}$ ao XXI, com as transformações mundiais em trânsito. Novas configurações emergem ou, pelo menos, são desejadas pela população e indicadas 
por especialistas. Em um contexto de turbulência e efervescência, nascem duas figuras portadoras de responsabilidades: o principal e o agente. Derivados da Teoria da Agência, de acordo com Rosseti e Andrade (2014), elas configuram-se como uma nova estrutura das organizações, em que os proprietários (principais) já não demandam mais a gerência de seus negócios, delegando-a aos agentes.

No caso do setor público, os principais são a população, enquanto os agentes são representantes eleitos, conselhos, autoridade máxima, dirigentes superiores, dirigentes e gerentes (Brasil, 2014). Segundo Slomski (2012), são três as funções clássicas do Estado. A primeira função diz respeito à alocação de recursos, tendo em vista a sua missão de atender às necessidades públicas. A segunda função do Estado é a da distribuição de renda, dada pelo sistema de tributação e transferência. Já a terceira função clássica do Estado, de acordo com o autor, é a de estabilização da moeda.

Nesse cenário, as responsabilidades assumidas pelos agentes requerem cuidados especiais, dentre estes se pode citar o respeito aos princípios da governança pública: transparência, integridade e accountabillity. A governança pública diz respeito às ações do Estado para promoção do bem-estar da sociedade, zelando pelas contas públicas.

Segundo o Plano Estratégico do Tribunal de Contas da União, "a governança pode ser descrita como um sistema pelo qual as organizações são dirigidas, monitoradas e incentivadas, envolvendo os relacionamentos entre sociedade, alta administração, servidores ou colaboradores e órgãos de controle" (Brasil, 2014, p. 21). A sociedade deve exercer seu papel de principal interessada nas decisões tomadas e ações realizadas na esfera pública, sendo que a liderança governamental precisa adotar um comportamento ético, profissional e focado no alcance de resultados que devem estar alinhados com os interesses da sociedade.

\subsection{Dimensões de governança segundo a IFAC}

Matias-Pereira (2010) relata a importância das contribuições e estímulos no processo de mudança na administração pública, por parte de organizações multilaterais e instituições privadas. O mesmo autor destaca algumas dessas principais instituições, com evidência para o Banco Mundial, Organização para a Cooperação e Desenvolvimento Econômico (OCDE), IFAC e Instituto Brasileiro de Governança Corporativa (IBGC), os quais estabelecem códigos de governança que têm grande importância. Para Slomski, Mello, Tavares Filho e Macêdo (2012), a governança no setor público abarca o modo como uma organização é adminis- 
trada, a estrutura corporativa, a cultura, as políticas, as estratégias e a maneira como a organização trata os diversos stakeholders. Isto é, a maneira como as organizações do setor público exercem as responsabilidades que Ihes são atribuídas, sendo transparentes, accountables e prudentes nas decisões, na elaboração de políticas e na execução dos programas.

Nessa perspectiva, tem-se a International Federation of Accountants (IFAC), uma organização mundial para a profissão contábil que tem como compromisso a proteção do interesse público, por meio do desenvolvimento de padrões e práticas internacionais de alta qualidade, da promoção de valores éticos e do suporte ao exercício da profissão em todos os setores. Em 2001, a IFAC publicou um estudo intitulado Governance in the public sector: a governing body perspective - Study 13 (IFAC, 2001), cujo objetivo foi contribuir para a boa governança e a accountability (obrigação de responder por uma responsabilidade conferida) no setor público. Desse modo, os princípios de governança são estabelecidos para sua aplicação em entidades do setor público.

A IFAC estabelece quatro dimensões para a governança na administração pública, que são: padrões decomportamento, estruturas organizacionais e processos, controle e relatórios externos. No presente trabalho, será apresentada e considerada apenas a dimensão "controle", pois o objeto de estudo desta pesquisa será o controle patrimonial de bens imóveis da UFSM.

As recomendações para a dimensão "controle" impostas pela IFAC (2001) estão divididas em cinco subdimensões:

- gestão de risco;

- auditoria interna;

- comitês de auditoria;

- controle interno e orçamento;

- treinamento de pessoal.

$\mathrm{Na}$ gestão de risco, os governos necessitam assegurar que sistemas efetivos de gestão de risco sejam estabelecidos como parte da estrutura de controle. O risco pode ser definido como uma medida de incerteza, e a compreensão dos fatores que o causam pode facilitar a realização dos objetivos da organização (IFAC, 2001).

A IFAC (2001) determina também que o gestor público e seus auxiliares devem assegurar que seja instituída uma função de auditoria interna efetiva, como parte da estrutura de controle, a menos que os custos de tal função excedam os benefícios dela resultantes. Um comitê de auditoria necessita ser estabelecido, compreendendo membros não executivos, com a responsabilidade para revisão independente das estruturas de controle e dos processos de auditoria externa (IFAC, 2001). 
O controle interno, na governança aplicada ao setor público, é entendido como um processo efetuado pela diretoria, pela gestão e por outras pessoas da entidade, designadas para prover razoável garantia à realização dos objetivos das seguintes categorias: efetividade e eficiência das operações, considerando objetivos operacionais básicos; metas de desempenho e proteção de recursos; confiabilidade dos relatórios financeiros; e conformidade com leis e regulamentos aplicáveis (IFAC, 2001).

O orçamento é um elemento essencial do planejamento financeiro, do controle e do processo de evolução da entidade do setor público. Pela sua natureza, ele é um meio de alocar recursos para atingir as metas e estruturar meios para alcançar os objetivos declarados (IFAC, 2001). O objetivo de um sistema de administração financeira, na gestão pública, é prestar suporte administrativo no desenvolvimento de recursos limitados, com o propósito de assegurar, econômica e eficientemente, a entrega do serviço (IFAC, 2001). Já o treinamento de pessoal determina a oferta de programas de treinamento específicos para servidores da área de controle, a fim de assegurar que estes desempenharão adequadamente o seu papel.

\section{MÉTODO DE PESQUISA}

Para verificar em quais aspectos o controle patrimonial de bens imóveis da UFSM atende às práticas de governança pública recomendadas pela IFAC na dimensão "controle", a presente pesquisa utilizou o método de estudo de caso único. Quanto aos objetivos, a pesquisa é caracterizada como descritiva e de abordagem qualitativa.

O estudo de caso contribui para compreender melhor os fenômenos individuais e os processos organizacionais e políticos da sociedade. É uma ferramenta utilizada para entender a forma e os motivos que levaram a determinada decisão. Conforme Yin (2001), o estudo de caso é uma estratégia de pesquisa que abrange tudo em abordagens específicas de coleta e análise de dados para uma determinada realidade.

A pesquisa descritiva, segundo Marconi e Lakatos (2003), refere-se a estudos que possuem, como função primordial, a exata descrição de certas características de populações, organizações ou outras coletividades específicas. De acordo com Yin (2001), a unidade de análise pode ser interpretada como: o indivíduo, uma prática cultural, um processo de trabalho, um grupo de pessoas ou mesmo a política e a estratégia organizacional. A definição da unidade de análise depende do objetivo que o pesquisador pretende atingir com o estudo de caso. 
O estudo abrange a atividade de controle patrimonial de bens imóveis da Universidade Federal de Santa Maria (UFSM) desempenhada por servidores que trabalham no Departamento de Material e Patrimônio (Demapa). Este é um órgão executivo da administração superior, na área de material e patrimônio, subordinado à Pró-Reitoria de Administração (PRA), que tem por finalidade coordenar, dirigir e executar as atividades relativas a licitações destinadas à aquisição de material, contratações de serviços e importações, controle patrimonial de bens móveis e imóveis, manutenção de estoques de material de consumo e sua distribuição a todas as subunidades, de acordo com a legislação vigente (UFSM, 2016).

Um questionário foi aplicado ao Pró-Reitor de Administração, devido à função que desempenha na estrutura da instituição e à devida correlação com o objetivo da pesquisa. Dada a natureza desta investigação, para a coleta de dados, foi realizada entrevista por meio de questionário enviado por e-mail com questões estruturadas. Segundo Prodanov e Freitas (2013), nessa técnica o entrevistador segue um roteiro preestabelecido, a partir de um formulário elaborado com antecedência, visto que, com a padronização, pode-se comparar grupos de respostas. A análise de conteúdo foi utilizada para julgamento das informações, por ser, segundo Bardin (2009), aplicável a qualquer comunicação. A autora define-a como um conjunto de técnicas de análise das comunicações visando obter, por procedimentos sistemáticos e objetivos de descrição do conteúdo das mensagens, indicadores (qualitativos ou não) que permitam a inferência de conhecimentos relativos às condições de produção/recepção (variáveis inferidas) dessas mensagens.

As respostas do entrevistado foram transcritas e logo após foi realizada a sua leitura flutuante, até ser dominado o todo do depoimento. A leitura flutuante consiste em tomar contato exaustivo com o material para conhecer seu conteúdo (Minayo, 2007). O termo "flutuante" é uma analogia à atitude do psicanalista, pois pouco a pouco a leitura se torna mais precisa, em função das hipóteses e das teorias que sustentam o material (Bardin, 2009).

\section{APRESENTAÇÃO E DISCUSSÃO DOS RESULTADOS}

Tendo em vista que a problemática de pesquisa se refere à governança de bens imóveis e que a unidade escolhida para análise foi uma Instituição Federal de Ensino Superior, este estudo restringiu-se à verificação dos controles realizados pela UFSM. A Universidade Federal de Santa Maria foi criada pela Lei $\mathrm{n}^{\circ}$ 3.834-C, de 14 de dezembro de 1960, e instalada solenemente em 18 de março de 1961, como uma Instituição Federal de Ensino Superior, vinculada ao Ministério 
da Educação como uma autarquia especial. Desde então, a UFSM expandiu seu território e construiu edificações para comportar suas unidades de ensino, prédios administrativos, laboratórios, restaurantes, ginásios e outros bens imóveis.

De acordo com as informações do Relatório de Gestão de 2015, a área territorial total da UFSM é de 1.837,72 ha, nos quais a área construída perfaz 328.048,04 m2no campus sede, além de 22.259,41 m2 em edificações no centro da cidade de Santa Maria. Possui, ainda, edificações nos municípios de Frederico Westphalen, Palmeira das Missões e Silveira Martins, com mais 36.661,49 m2 de área. Até dezembro de 2015, a área total construída da UFSM era de 386.968,94 m2.

O campus sede da UFSM, que abrange a Cidade Universitária "Prof. José Mariano da Rocha Filho", está localizado no bairro Camobi, em Santa Maria, onde é realizada a maior parte das atividades acadêmicas e administrativas. Funcionam no centro da cidade outras unidades acadêmicas e de atendimento à comunidade, e os demais campi da universidade situam-se nas cidades de Cachoeira do Sul, Frederico Westphalen e Palmeira das Missões.

$\mathrm{Na}$ estrutura do campus sede da instituição, há três restaurantes universitários (dois no campus e um no centro da cidade de Santa Maria); Biblioteca Central e bibliotecas setoriais, Hospital-Escola, que, atualmente, está sob a gestão da Empresa Brasileira de Serviços Hospitalares (EBSERH); Hospital Veterinário Universitário; Farmácia-Escola; Museu Educativo; Planetário; Usina de Beneficiamento de Leite; Orquestra Sinfônica; Coordenadoria de Comunicação (responsável pela Rádio, TV e Núcleo de Comunicação Institucional da universidade); laboratórios e prédios das Unidades de Ensino.

As informações relacionadas aos bens de uso especial da União sob a gestão da UFSM se encontram registradas no Sistema de Gerenciamento do Patrimônio Imobiliário de Uso Especial da União (SPIUnet) e no Sistema Integrado de Administração Financeira do Governo Federal (Siafi).

Atualmente, a UFSM administra 108 imóveis, entre próprios, alugados ou cedidos a terceiros (empresas, estudantes, órgãos públicos e servidores públicos). Quatro destes são bens imóveis de uso especial locados de terceiros, sem registro no SPIUnet, a exemplo do prédio do campus de Cachoeira do Sul.

A administração desses bens demanda um trabalho dinâmico, capaz de garantir que cada imóvel público cumpra a sua função social prevista pela Constituição Federal de 1988, sendo necessário, para tanto, o monitoramento constante referente à sua conservação, ocupação e valorização. Atualmente, essa gestão é feita de forma conjunta pelas pró-reitorias da instituição. 
Porém, no que tange à Gestão do Patrimônio Imobiliário, de acordo com o relatório de Solicitação de Auditoria n 20153673/008, de 22 de junho de 2015, a Controladoria Geral da União encontrou as seguintes falhas no controle de imóveis pela UFSM:

a. inocorrência de registro contábil de cada bem imóvel, de forma individualizada, no ativo imobilizado, com seu respectivo valor;

b. inocorrência de registro específico, no SPIUnet, de cada bem imóvel;

c. inexistência de carta autorizativa para utilização de edificações (habite-se).

Importante destacar que, no relatório de auditoria de 2011, a Controladoria já havia apontado falhas na gestão dos Bens de Uso Especial da União sob responsabilidade da UFSM, especialmente por considerar insuficientes os controles realizados.

As falhas relatadas naquele período foram relacionadas à perda de validade das avaliações de bens imóveis, que, para fins de registros contábeis, não poderia ultrapassar o período de 24 meses; à inconsistência de informações entre o SPIUnet e o Relatório de Gestão da instituição, posto que os Bens Imóveis de Uso Especial Locados de Terceiros não possuíam registro no SPIUnet; e à falta de controle específico de gastos com a manutenção desses imóveis (Relatório de Auditoria Anual de Contas n²01203068/2011-CGU).

Ainda de acordo com o referido relatório, naquele período, as informações alusivas ao Hospital Universitário de Santa Maria, tanto no SIAFI quanto no SPIUnet, estavam associadas à Unidade Gestora da UFSM, sem haver separação por unidades gestoras. Além disso, no mesmo texto, a auditoria considerou falhos o acompanhamento dos dados relativos às edificações e a geração de informações que auxiliassem a UFSM no controle e monitoramento desses bens, principalmente, no controle das edificações que sofreram interrupções contratuais, bem como invasões ou ocupações irregulares.

Dessa forma, para atendimento do Plano de Implantação dos Procedimentos Contábeis Patrimoniais (Anexo à Portaria $n^{\circ} 548$, de 24 de setembro de 2015) e das orientações técnicas da Controladoria Geral da União, a instituição designou, em 15 de julho de 2016 (Portaria UFSM n 80.277/2016), uma Comissão para Avaliação/Reavaliação dos Bens Imóveis da UFSM, registrada no SPIUnet, com a previsão de conclusão dos trabalhos em dezembro de 2016.

Além disso, de acordo com a Pró-Reitoria de Administração, está sendo implantado o Módulo de Contratos no Sistema de Informações de Ensino (SIE), 
como ferramenta voltada ao monitoramento e acompanhamento dos contratos, inclusive contratos de obras em andamento. Isso porque o referido sistema de informação fornece um suporte fundamental na gestão dos contratos, por meio da disponibilização de informações atualizadas sobre os valores contratados, aditivos, supressões e emissão de relatórios, como um mecanismo de controle institucional. Nesse sentido, a implantação do Módulo de Contratos, a adequação da gestão dos imóveis sob a gestão da UFSM e a formação de equipe para a reavaliação dos bens imóveis e atualização dos dados no SPIUnet e SIAFI são medidas adotadas pela administração para adequação dos sistemas de controle interno e sujeição às normas de controle patrimonial da União.

A análise quanto ao controle patrimonial dos bens imóveis da União sob a gestão da UFSM passa necessariamente pela coleta de informações no SPIU, tendo em vista ser o sistema de monitoramento dos bens imóveis da União, cuja fiscalização é exercida pela SPU.

Assim, a partir das informações fornecida sem Relatório Sintético do SPIUnet, verificou-se que a Unidade Gestora 153164 - Universidade Federal de Santa Maria possui $\mathrm{R} \$ 317.497 .851,83$ (trezentos e dezessete milhões, quatrocentos e noventa e sete mil, oitocentos e cinquenta e um reais com oitenta e três centavos) como Imóveis de Uso Especial da União, distribuídos por Registro Individualizado Patrimonial - RIP do Imóvel, subdivididos em Registro Individualizado Patrimonial - RIP de Utilização.

Desse modo, os Imóveis de Uso Especial da União devem ser cadastrados no SPIUnet, gerando, assim, um Registro Imobiliário Patrimonial (RIP), que se subdivide em: RIP imóvel, que corresponde ao cadastro do imóvel no total, resultando na soma dos RIPs de utilização; e RIP Utilização, que corresponde à utilização de um imóvel ou parte dele por uma determinada Unidade Gestora (UG). Se o mesmo imóvel é utilizado por mais de uma UG, deverá ser criada uma Utilização para cada uma.

Em síntese, no SPIUnet, o RIP Imóvel contém as informações referente ao imóvel e o RIP Utilização contém as informações referente às benfeitorias do imóvel. Vale destacar que, no SIAFI, o que aparece é o RIP Utilização, chamado de "Conta Corrente", como seu respectivo valor, localizado no campo "Valor da Utilização".

De qualquer modo, para avaliar a adequabilidade dos controles administrativos da UFSM no que tange ao controle patrimonial dos Bens Imóveis de Uso Especial da União, é necessário o confronto do saldo da conta Imóveis de Uso Especial no Balancete com o valor apresentado na opção Consulta Contabilização SIAFI, no sistema SPIUnet. Tal procedimento assegurará a correta contabi- 
lização dos imóveis, mantendo a contínua e tempestiva compatibilidade entre as informações existentes nos dois sistemas (Portaria Interministerial $n^{\circ} 322$, de 23 de agosto de 2001).

A seguir, são apresentados os resultados obtidos a partir do questionário aplicado junto ao Pró-Reitor Administração da instituição. O questionário preocupou-se em abordar questões referentes ao controle patrimonial de bens imóveis da UFSM com base nas dimensões de governança pública estabelecidas pela organização IFAC. Para o alcance dos objetivos propostos, elaboraram-se cinco questões, que foram encaminhadas por e-mail ao entrevistado no mês de novembro de 2016.

Quando questionado sobre quais medidas a direção tem tomado para garantir que sistemas eficazes de gestão de riscos sejam estabelecidos como parte da estrutura de controle interno, o entrevistado observou que várias ações têm sido tomadas: São várias as ações que estão sendo tomadas como um todo para gestão, principalmente na reestruturação do Sistema de Informação para Ensino (SIE), com o fim de produção de relatórios gerenciais. Especificamente na questão do controle da carga patrimonial dos Bens Imóveis, são atribuições da Pró-Reitoria de Infraestrutura, e todos os Imóveis da UFSM têm tratamento no Sistema do Governo Federal, SPIUnet, controlado pelo DCF e com uma comissão de reavaliação recentemente reestruturada e coordenada por um Servidor da PRA.

Sobre as medidas que a direção tem realizado para garantir que uma função de auditoria interna eficaz seja estabelecida como parte da estrutura de controle interno, o pesquisado tem como principal medida o registro de informações SPIUnet, conforme se pode observar no seguinte trecho: "As medidas são um conjunto de ações conforme acima relatado, mas a medida principal é o registro de todos os imóveis no SPIUnet, sistema do Governo Federal e Comissão de Reavaliação que cumpre as normas de reavaliação para registro contábil."

Quando questionado sobre a existência de um comitê de auditoria para o controle patrimonial de bens imóveis da UFSM composto por membros não integrantes da direção, responsável pela revisão independente da estrutura de controle, e se o processo de auditoria externa funciona na prática, o entrevistado mencionou que existe uma auditoria interna, além dos órgãos de controle do governo:

Na UFSM, existe uma Auditora Interna que de forma independente, ligada ao Conselho Universitário (CONSU), realiza as auditorias de todas as áreas da instituição. Existem ainda os órgãos de controle do Governo Federal, antiga CGU, hoje Ministério da Transparência, que fazem auditorias, inclusive com recomendações e enquadramentos. 
A partir do questionamento sobre como são estabelecidas as medidas para garantir uma estrutura de controle interno eficaz referente ao controle patrimonial de bens imóveis e como a direção inclui em seu relatório anual informações sobre a efetividade da estrutura de controle interno do patrimônio de bens imóveis, entende-se que essa questão tem como base a Comissão de Reavaliação, conforme fala do entrevistado:

A questão dos bens imóveis está toda centrada no sistema do Governo Federal e na Comissão de Reavaliação, todo patrimônio imóvel da Instituição na parte territorial está escriturado e cadastrado nos registros de imóveis dos municípios a que pertence, o controle do espaço físico é de responsabilidade da Pró-Reitoria de Infraestrutura, que mantém plantas e registros atualizados.

Diante do questionamento sobre o modo como é estabelecido o programa de treinamento para garantir que os servidores da instituição sejam capazes de realizar as tarefas que lhes são atribuídas referentes ao controle patrimonial de bens imóveis, observa-se que há programas de treinamento e o principal deles é o ciclo da contratação pública, conforme comenta o entrevistado:

São várias as capacitações que são realizadas pela Pró-Reitoria de Planejamento (Proplan), Departamento de Material e Patrimônio (Demapa), Departamento de Contabilidade e Finança (DCF), Pró-Reitoria de Administração (PRA). A principal é o Ciclo da Contratação Pública, com várias edições desde o ano passado. Cito, também, a gestão de contratos e gestão de contratos terceirizados.

A partir das respostas apresentadas, percebe-se inicialmente que há um controle interno próprio da UFSM, além do controle dos órgãos e sistemas do governo. Esse controle é feito a partir de informações disponibilizadas no sistema pela Pró-Reitoria de Infraestrutura; a partir daí esse registro é controlado pelo DCF e pela Comissão de Reavaliação recentemente reestruturada e coordenada por um servidor da PRA.

\section{CONSIDERAÇÕES FINAIS}

Esta pesquisa objetivou analisar o controle patrimonial dos bens imóveis da UFSM com base nas dimensões de governança pública estabelecidas pela organização IFAC considerando a dimensão "controle". Accountability é uma denominação que se discute no meio acadêmico em relação à sua tradução e sua possível incorporação à gestão pública brasileira tanto no setor privado como no setor público. Neste artigo, o termo pode ser traduzido, de forma simples, como responsabilização pela gestão. 
De acordo com os resultados apresentados, segundo as práticas de governança estabelecidas em termos de informações a serem disponibilizadas pelas organizações públicas, o controle deve atender ao conteúdo mínimo apresentado nas cinco subdimensões indicadas neste trabalho: gestão de risco, auditoria interna, comitês de auditoria, controle interno e orçamento e treinamento de pessoal. Dessa forma, os resultados da pesquisa, de um modo geral, demonstram a absorção, pela UFSM, de valores e princípios mínimos de governança recomendados pela IFAC, pois observa-se a adoção de boas práticas, o que implica transparência e promoção da accountability para a instituição.

Verifica-se também que o processo de controle patrimonial de bens imóveis da UFSM atende às práticas de governança pública recomendadas pela IFAC na dimensão "controle", o que pode ser corroborado por questões já relatadas. Ainda, afirma-se que os procedimentos utilizados no controle patrimonial de bens imóveis da UFSM são basicamente os sistemas de controle do governo federal. O estudo apresentou algumas limitações, como, por exemplo, o fato de os resultados não poderem ser generalizados a outras realidades, pois a entrevista foi aplicada a apenas um indivíduo, além de ter sido utilizada uma métrica apenas, a da IFAC, para verificar aspectos de governança. Sugere-se, como futuras pesquisas, a verificação de práticas adotadas na UFSM em relação a todas as Dimensões de Governança determinadas pela IFAC, bem como a verificação da governança por outras perspectivas, diferentes da IFAC, e a comparação da UFSM com outras instituições, por meio de um estudo multicaso.

\section{REFERÊNCIAS}

Bardin, L. (2009). Análise de conteúdo. (5. ed.). Lisboa: Edições 70.

Bernardes, J. F. (2009). Administração patrimonial nas instituições públicas federais no contexto da gestão do conhecimento. (Tese de doutorado) Universidade Federal de Santa Catarina, Florianópolis, SC, Brasil.

Brasil. Tribunal de Contas da União. (2014). Governança Pública: Referencial básico de governança aplicável a órgãos e entidades da administração pública e ações indutoras de melhoria. / Tribunal de Contas da União. Brasília: TCU, Secretaria de Planejamento, Governança e Gestão.

Gil, A. C. (2007). Métodos e técnicas de pesquisa social. São Paulo: Atlas.

IFAC. (2001). Governance in the public sector: A governing body perspective international public. Sector. Study 13, IFAC.

Matias Pereira, J. (2010). Governança no setor público. São Paulo: Atlas. 
CONTROLE PATRIMONIAL DE BENS IMÓVEIS COM BASE NAS DIMENSÕES DE GOVERNANÇA PÚBLICA

Minayo, M. C. S. (2007). O desafio do conhecimento: Pesquisa qualitativa em saúde. (10. ed.). São Paulo: Hucitec.

Pinho, J. A. G. de, \& Sacramento, A. R. S. (2009, novembro/dezembro). Accountability: já podemos traduzi-la para o português? RAP: Revista de Administração Pública, 43(6), 1343-1368.

Prodanov, C. C., \& Freitas, E. C. de. (2013). Metodologia do trabalho científico: Métodos e técnicas da pesquisa e do trabalho acadêmico. (2. ed.). Novo Hamburgo: Feevale.

Rosseti, J. P., \& Andrade, A. (2014). Governança corporativa: Fundamentos, desenvolvimento e tendências. (7. ed.). São Paulo: Atlas.

Slomski, V. (2012). Controladoria e governança na gestão pública. São Paulo: Atlas.

Slomski, V., Mello, G. R., Tavares Filho, F., \& Macêdo, F. Q. (2012). Governança Corporativa e Governança da Gestão Pública. São Paulo: Atlas.

UFSM. Portal UFSM Indicadores. Recuperado de http://portal.ufsm.br/indicadores/ index;jsessionid=d12b9f6f05714b846a4e159746bd

Yin, R. K. (2001). Estudo de caso: Planejamento e métodos. Porto Alegre: Bookman. 